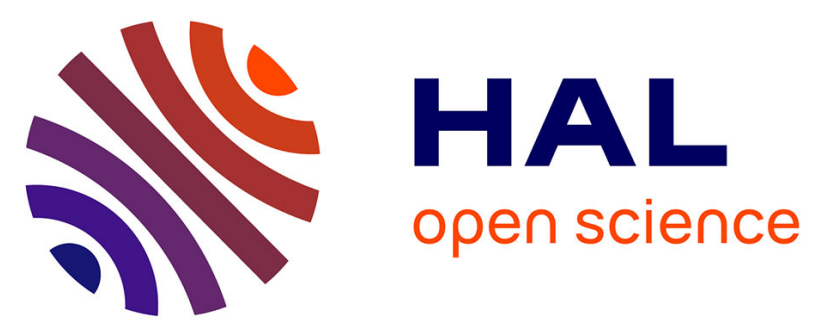

\title{
Association between Cognitive Status before Surgery and Outcomes in Elderly Patients with Hip Fracture in a Dedicated Orthogeriatric Care Pathway
}

\author{
Lorene Zerah, Judith Cohen-Bittan, Mathieu Raux, Anthony Meziere, \\ Cendrine Tourette, Christian Neri, Marc Verny, Bruno Riou, Frederic Khiami, \\ Jacques Boddaert
}

\section{To cite this version:}

Lorene Zerah, Judith Cohen-Bittan, Mathieu Raux, Anthony Meziere, Cendrine Tourette, et al.. Association between Cognitive Status before Surgery and Outcomes in Elderly Patients with Hip Fracture in a Dedicated Orthogeriatric Care Pathway. Journal of Alzheimer's Disease, 2016, pp.1-12. 10.3233/JAD-160655 . hal-01414826

\section{HAL Id: hal-01414826 \\ https: / hal.sorbonne-universite.fr/hal-01414826}

Submitted on 12 Dec 2016

HAL is a multi-disciplinary open access archive for the deposit and dissemination of scientific research documents, whether they are published or not. The documents may come from teaching and research institutions in France or abroad, or from public or private research centers.
L'archive ouverte pluridisciplinaire HAL, est destinée au dépôt et à la diffusion de documents scientifiques de niveau recherche, publiés ou non, émanant des établissements d'enseignement et de recherche français ou étrangers, des laboratoires publics ou privés. 
Association between cognitive status before surgery and outcomes in elderly patients with hip fracture in a dedicated orthogeriatric care pathway

Lorene Zerah $^{\mathrm{a}, \mathrm{b}}$, Judith Cohen-Bittan ${ }^{\mathrm{a}}$, Mathieu Raux ${ }^{\mathrm{b}, \mathrm{c}}$, Anthony Meziere ${ }^{\mathrm{d}}$, Cendrine

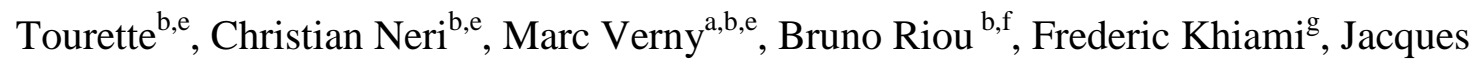
Boddaert $^{\mathrm{a}, \mathrm{b}, \mathrm{e}}$

a. Department of Geriatrics, Unit of Peri-Operative Geriatric care, Groupe Hospitalier (GH) Pitié-Salpêtrière, Assistance Publique-Hôpitaux de Paris (APHP), Paris, France

b. Sorbonne University, University Pierre and Marie Curie (UPMC) Paris 06, University Hospital Department Fight Aging and Stress (DHU FAST), Paris, France

c. Departments of Anesthesiology and Critical Care, GH Pitié-Salpêtrière, APHP, Paris, France

d. Department of Rehabilitation, GH Charles Foix, APHP, Ivry sur Seine, France

e. Centre National de la Recherche Scientifique (CNRS), UMR 8256

f. Departments of Emergency Medicine and Surgery, GH Pitié-Salpêtrière, APHP, Paris, France

g. Departments of Orthopedic Surgery and Trauma, GH Pitié-Salpêtrière, APHP, Paris, France

Corresponding author: Pr. Jacques Boddaert, Unit of Peri-Operative Geriatric care, GH Pitié-Salpêtrière, 47-83 Boulevard de 1'Hôpital, 75013 Paris, France.

Tel: +33 1 42164117; Fax: +33 1 42160626; Email: jacques.boddaert@aphp.fr

Running title: Dementia and prognosis of hip fracture 


\section{Abstract (word count: 250)}

Background: Dementia is associated with a worse prognosis of hip fracture, but the impact of a dedicated geriatric care pathway on the prognosis of these patients has not been evaluated.

Objective: According to the cognitive status before surgery, our main objective was to compare mortality rate at 6 months; secondary outcomes were to compare in-hospital complications, the risk of new institutionalization and the ability to walk at 6 months. Methods: Between 2009 and 2015, all patients (> 70 years) admitted after hip fracture surgery into a dedicated unit of peri-operative geriatric care were included: patients with dementia (DP), without dementia (NDP) and with cognitive status not determined (CSND). Data are expressed as Hazard Ratio(HR) for multivariate cox analysis or Odds Ratio(OR) for multivariate logistic regression analysis and their $95 \%$ confidence interval (CI).

Results: We included 650 patients ( $86 \pm 6$ years): 168 DP, 400 NDP and 82 CSND. After adjustment for age, sex, comorbidities, polypharmacy, pre-fracture autonomy, time-to-surgery and delirium, there were no significant differences for 6-month mortality (DP vs NDP: $\mathrm{HR}=0.7[0.4-1.2]$, DP vs CSND: $\mathrm{HR}=0.6[0.3-1.4]$, CSND vs NDP: $\mathrm{HR}=0.8[0.4-1.7]) ;$ but DP and CSND were more likely to be newly institutionalized after 6 months compared to NDP (OR DP=2.6[1.4 - 4.9], p=0.003, OR CSND=2.9[1.4 - 6.1], $\mathrm{p}=0.004) .92 \%$ of population was walking after 6 months (63\% with assistance): no difference was found between the 3 groups.

Conclusion: In a dedicated geriatric care pathway, DP and CSND undergoing hip surgery have the same 6-month mortality and walking ability as NDP.

$\underline{\text { Key words: }}$ Unit of Peri-Operative Geriatric care, Hip fracture, Dementia, Elderly 


\section{Introduction}

As a consequence of the aging of the population, the incidence of osteoporotic fractures, especially hip fractures (HF), is increasing [1,2]. In 2000, the worldwide incidence of HF was estimated at 1.6 million in people aged 50 years and older [1]. The annual global incidence of HF is expected to rise to between 7.3 and 21.3 million by the year 2050 [3]. Nearly all HF occur as a result of a fall and many fall again soon after sustaining the fracture [4]. Direct medical costs incurred are staggering, estimated at between US \$153.5 billion and US $\$ 446.3$ billion annually by 2050 [5]. The rate of death is high, varying from 12 to $23 \%$ during the 6 months following the fracture, higher than in the general population in the following months and years $[6,7]$.

Dementia affects 36 million people worldwide, with numbers expected to double every 20 years to 66 million by 2030 [8]. Among dementia, notably in the geriatric population, Alzheimer's disease (AD) is the most frequent neurodegenerative disorder [9], but cognitive impairment remains under diagnosed [8]. In 2009, Sampson et al. showed that $42 \%$ of unselected older medical inpatients had dementia, half of these had not previously been diagnosed with dementia[10].

AD and HF are closely related [11]. Baker and al. found that patients with AD had a 3.2 hazard ratio for risk of $\mathrm{HF}(95 \% \mathrm{CI}, 2.4-4.2)$ compared to non-AD patients, after controlling for potential confounders [12]. In their study, the incidence of HF among patients with and without $\mathrm{AD}$ was 17.4 (95\% CI, 15.7-19.2) and 6.6 (95\% CI, 5.8-7.6) per 1,000 person years, respectively [12]. In particular, mortality and poor functional recovery after HF seem to be more frequent in patients with dementia than in patients without dementia [12-15]. Among the patients who experienced a HF, 24 to $27 \%$ of patients with dementia and 10 to $14 \%$ of patients without dementia did not survive more than six months after the occurrence of a HF $[7,12]$. 
Because most of HF occur in older patients, the prevalence of comorbid conditions and frailty is high among this population $[16,17]$. They are at high risk of developing complications such as delirium, infection and drug related problems. Recently, there has been an increasing interest for the development of collaborations between orthopedic surgeons, anesthesiologists and geriatricians. Hospitals and health systems have implemented ortho-geriatric care to improve patient outcomes, with conflicting results [2,4,18-25].

In a previous study [26], we demonstrated that early admission to a dedicated geriatric unit improved 6-month mortality and morbidity in elderly patients with HF. Our study did not focus on patients with dementia (38\% of our population). However, the question of the benefit of a dedicated geriatric unit post HF in patients with dementia is still unexplored.

Our hypothesis was that, whatever the cognitive status before surgery, all patients admitted with hip fracture in an orthogeriatric-dedicated care pathway, with staff trained to manage patients with dementia, would have the same prognosis at 6 months. Our main objective was to compare mortality rate at 6 months regarding the cognitive status before surgery. Secondary outcomes were to compare: in-hospital complications, including delirium; the risk of new institutionalization and the ability to walk at 6 months, according to the cognitive status before surgery. 


\section{Materials and Methods}

This study was approved by the hospital ethics committee (CPP Ile de France VI, Paris, France), and informed consent was waived, as the study was observational. The database was declared to the French National Commission on Computing and Liberty (CNIL, Paris, France).

\section{$\underline{2.1 \text { Study population }}$}

From July 2009 to December 2015, all patients admitted to our emergency department (ED) were evaluated for eligibility. Detailed methodology including the opening of a new geriatric unit (UPOG: Unit for Peri-Operative Geriatric care) has been previously reported [26], and some of these patients were included in previous studies [26,27]. Patients were included if their primary admission was due to HF and if they were aged over 70. Patients were not included if they were admitted with multiple fractures, a metastatic fracture or a fracture complicated by a previous hip prosthesis or osteosynthesis.

Their cognitive status before surgery was obtained from the patients themselves, family members, caregivers and from their general practitioners who were systematically contacted (phone call), and determined as follows:

1- Patients with dementia (DP): with a previous diagnosis of dementia by a geriatrician or a neurologist using internationally recognized criteria and DSM-IV criteria [8-10,28]. These patients had had a cognitive screening with a neuropsychologist using screening instruments and a cerebral imaging. Some of them were treated by specific treatments (anticholinesterase inhibitors or antiglutamate) that only neurologists, psychiatrists and geriatricians are authorized to prescribe in France.

2- Patients without dementia (NDP): with no known previous cognitive impairment, without memory or cognitive complaint before admission to our hospital (according to family and to general practitioner), without specific treatment and still complaint-free at 6 months. Because 
they were not included in DSM-IV criteria that defined dementia, it is to note that these patients did not have a complete cognitive assessment with a neuropsychologist before or after the hospitalization.

3- Patients with cognitive status not determined (CSND): with a history of previous cognitive impairment without cognitive evaluation or conclusive cognitive evaluation (unexplored or unlabeled). As detailed in the introduction, there are a significant proportion of patients under diagnosed $[8,10]$. In this group, patients possibly had dementia, mild cognitive impairment (MCI) or other conditions with cognitive consequences. Without an accurate diagnosis, we have chosen to create this third group of patients.

\section{$\underline{2.2 \text { Design study }}$}

The data were prospectively entered in the database, including age, sex, own home or nursing home, living conditions, walking ability, medical history, type of fracture and surgical treatment, time-to-surgery (delay) and duration of surgery. Co-morbidity severity was assessed using the Cumulative Illness Rating Scale (CIRS-G) [29] in which co-occurring medical conditions are weighted from 0 to 4 in 13 main systems. Pre-hospitalization functional status was assessed using the Activities of Daily Living (ADL) scale[30]. We recorded preoperative hemoglobin level and its lowest value during the hospitalization, serum creatinine and estimated creatinine clearance using the Cockcroft formulae. All complications during the hospitalization were recorded, including delirium using the Confusion Assessment Method scale [31] (assessment on arrival and then once a day consistently), use of physical restraints, stool impaction, urinary retention requiring drainage, morphine administration, pressure ulcer, infection, phlebitis or pulmonary embolism, blood transfusion, cardiac insufficiency (i.e. acute cardiac failure or acute pulmonary edema), and admission into an intensive care unit (ICU). To prevent and manage the occurrence of possible delirium, we used the recommendations proposed by Inouye et al. (non-pharmacological and 
pharmacological acute treatment strategies) [31,32]. Management strategy focused on early mobilization with the aim of chair-sitting and walking (first steps) within 24 and 48 hours. Patients were studied until death or 6 months after admission, for survival, walking ability (outdoors, with or without assistance) and new institutionalization. Surviving patients or their relatives were evaluated in the usual ambulatory clinic assessment, or contacted and interviewed by telephone; ADL scale and MMSE (Mini-Mental State Examination) were usually done $[8,10]$. Missing patients were tracked through health care providers, particularly general practitioners, or any identified acquaintances. The primary endpoint was 6-month mortality and secondary endpoints were i) 6-month functional outcome including new institutionalization and ability to walk ii) postoperative complications including delirium. Our study compared the 3 groups of patients, in pairs: patients with dementia (DP), patients without dementia (NDP) and patients with cognitive status not determined (CSND).

\section{$\underline{2.3 \text { Statistical analysis }}$}

Data are presented as mean $\pm \mathrm{SD}$, median [25-75 interquartile] for non-Gaussian variables, or number (percentages). Comparisons between 3 groups were performed using a Kruskal Wallis test for quantitative variables, followed by a Dunn test when a significant difference was found; and Fisher's exact method for qualitative variables. Survival and the risk of a new institutionalization in the 3 groups of patients were estimated by a multivariate logistic regression analysis and for survival by the Kaplan-Meier method too (differences were assessed by the log-rank test) adjusted for the factors known in the published literature $[6,12$ $15,19,26,33,34]$ (semi-parsimonious method): age $(<80,81-85,86-90,>90)$, sex (female as reference), comorbidities (CIRS-G, $\leq$ or $>8$ ) [29], number of drugs per day ( $<$ or $\geq 5$ ), prefracture ADL6 $(\leq 5$ or $=6$ ) [30], the ability to walk without assistance before surgery, time-tosurgery ( $\leq$ or $>48$ hours) and the occurrence of delirium during hospitalization. We tested the association of survival / new institutionalization and cognitive status before surgery in UPOG 
by calculating the odds ratio (OR) or Hazard ratio (HR) and their 95 percent confidence interval (CI) with these prognostic variables. There was 11 missing data (lost of follow-up) for death at 6 months and new institutionalization at 6 months; we excluded these patients from the main analysis $(1,7 \%)$.

To assess the weight of dementia in some intra-hospital complications (delirium), admission to rehabilitation care after hospitalization, a multivariate logistic regression analysis was performed and adjusted for the same factors. All $\mathrm{P}$ values were two-sided and $\mathrm{P}<0.05$ was considered significant. R software 3.3.1 was used for statistical analyses (www.cran.rproject.org last date accessed August 10, 2016).

\section{Results}

\subsection{Characteristics of the population and the 3 groups of patients before $\mathrm{HF}$}

Among the 711 patients with HF admitted to the ED, 650 were included (mean age $86 \pm 6$ years; 495 (76\%) female, median CIRS-G: 9[6 - 12]): 168 patients with dementia (DP: 26\%), 400 patients without dementia (NDP: $61 \%$ ) and 82 with cognitive status not determined (CSND: 13\%) (Figure 1).

Cardiovascular comorbidities were more prevalent (Table 1), 97\% of patients previously walked, with assistance in $51 \%$ of cases (cane, walking frame, human assistance). Baseline characteristics are presented in Table $\mathbf{1 .}$

Among patients with a previous diagnosis of dementia, 59\% $(\mathrm{n}=99)$ of them had a diagnosis of Alzheimer's disease, $9 \%(n=15)$ of them had a diagnosis of vascular dementia, $17 \%(\mathrm{n}=$ 28) of them had a diagnosis of Alzheimer's disease and vascular dementia, 7\% ( $\mathrm{n}=11)$ of them had a diagnosis of dementia associated with Parkinson's disease, $8 \%(n=13)$ of them had a Lewy body disease, 1 patients suffered from corticobasal degeneration and 1 from multisystem atrophy. 
Among CSND patients, $20 \%$ of them $(n=19)$ had a cognitive assessment before HF without a diagnosis. Reported by family and / or the general practitioner and / or the patient, memory complaint was the main symptom in $68 \%(\mathrm{n}=56)$ of cases, behavioral disorders (aggressiveness or apathy) in 5\% ( $n=4)$ of cases, and both in $27 \%(n=22)$ of cases.

DP and CSND patients differed from NDP patients (table 1): they were older, had more comorbidities and were less autonomous : they had a pre-fracture ADL 6 lower than NDP patients, they were more often institutionalized, and, when they lived at home, DP patients needed more assistance. In the same way, CSND patients differed from DP patients (table 1): they were older, they had a pre-fracture ADL6 higher than DP patients, they were less often institutionalized and, when they lived at home, they needed less often assistance. DP patients were more at risk of repeated falls. There was no significant difference between the 3 groups considering care (type of surgery, time to surgery, time to the UPOG, duration of surgery).

\subsection{Hospitalization: complications and discharge}

Other post-operative complications are described in Table 2. During hospitalization, 39\% of patients suffered from delirium. Delirium appeared more often in DP $(n=99,59 \%)$ and CSND $(n=50,61 \%)$ patients than in NDP patients $(n=105,26 \%)$, without difference between DP and CSND patients. DP patients had a OR that was 3.12 (95\% CI[1.97 - 4.96]) times higher that NDP patients; CSND patients had a OR that was 3.30 (95\% CI[1.87 - 5.80]) times higher that NDP patients $(\mathrm{p}<0.001)$ after controlling for potential confounders (table 3).

At discharge from the hospital, they were no difference in walking (few steps) between the 3 groups, but DP patients less frequently benefited from rehabilitation stay than NDP and CSND patients (respectively: 67\%,84\%,80\%). Nevertheless, after controlling for potential confounders (table 3), no difference was found between the 3 groups. 


\subsection{Mortality rate at 6 month}

At 6 month, $15 \%$ of patients were dead (table 2). In univariate analysis, no difference was found between DP/NDP patients (16\% vs 14\%) and CSND/DP patients (22\% vs 16\%) for the 6-months mortality rate. There was a significant difference between CSND patients (22\%) and NDP patients (14\%) (Table 2). After controlling for potential confounders (multivariate logistic regression analysis and cox regression analysis), no difference was found (Table 3,

Figure 2, Appendix 1-2-3): DP vs NDP patients (HR=0.67 95\% CI [0.38 - 1.20], p=0.19), DP vs CSND patients (HR=0.65 95\% CI [0.28 - 1.45], p=0.29), CSND vs NDP patients $(\mathrm{HR}=0.8495 \%$ CI $[0.41-1.68], \mathrm{p}=0.62)$.

\subsection{Functional outcomes at 6 month (walk and new institutionalization)}

Considering functional outcome, $92 \%$ of the patients were walking after 6 months $(63 \%$ with assistance). No difference was found between 3 groups for walking with assistance: $64 \%$ of NDP, $61 \%$ of DP and $62 \%$ of CSND patients (Table 2 ).

No difference was found between CSND and DP patients for new institutionalization at 6 months in univariate analysis (23\% vs $19 \%)$. In contrary, DP patients were more frequently newly institutionalized than NDP patients at 6 months (19\% vs 8\%), as CSND patients compared to NDP patients at 6 months (23\% vs 8\%) (Table 2). After controlling for potential confounders (multivariate logistic regression analysis, Table 3), the difference still remains for DP patients vs NDP patients (OR=2.56 95\% CI [1.36 - 4.86], p=0.003) and CSND patients vs NDP patients (OR=2.91 95\% CI [1.37 - 6.07], $\mathrm{p}=0.004)$.

DP and CSND patients had lower ADL score at 6 months that NDP patients (respectively 2[1 - 4], 3[2-5] and 5[3-6]), and the difference was also significant between CSND and DP patients (table 2).

At 6 month, 17\% of CSND patients (14 patients) had had a neurocognitive assessment with a diagnosis of Alzheimer's diseases $(n=4)$, vascular dementia $(n=3)$, Alzheimer's disease and 
vascular dementia $(n=1)$, Lewy body disease $(n=1)$, supranuclear paralysis $(n=2)$, and 2 without a diagnosis. Considering patients without cognitive assessment, 17 had a MMSE score $<11,15$ a MMSE score > 25, 5 patients did not speak french, 3 refused any assessment. For 28 patients, we did not have cognitive data at 6 months.

\section{Discussion}

To our knowledge, this is the first study considering the association between cognitive status before surgery and mortality and functional outcomes when geriatricians, together with other specialists in an orthogeriatric dedicated care pathway, manage patients with HF. Interestingly, and despite a higher risk of new institutionalization for patients with dementia and cognitive status not determined, we report a lack of significant difference in 6-month mortality and walking ability between the 3 groups of patients (DP, NDP and CSND).

\subsection{Outcomes}

These results differ from the published literature in the field where mortality and functional recovery after HF in patients with dementia appear to be worse compared to patients without dementia [12-15] and where patients with dementia benefited less often from rehabilitation services, whose role in the recovery of autonomy and mobility has been repeatedly demonstrated [35,36]. In our population, the mortality rate at 6 months in patients with dementia $(16 \%)$ or patients with cognitive status not determined $(22 \%)$ was lower that the rate reported in the literature (24 to $27 \%)[7,12]$.

These results suggest, in agreement with other published studies investigating the role of an orthogeriatric assessment $[4,18-25]$, that the management of elderly people with HF should systematically consider a geriatric expertise. Indeed, (1) the management of multimorbidity and frailty in the elderly; (2) a quick surgery and an appropriate anesthesia protocol for the elderly; (3) a prevention of common post-operative complications such as delirium; (4) an 
assessment of the risk-benefit ratio of treatments (especially analgesics); (5) a management strategy focused on early mobilization with the aim of chair-sitting and walking (first steps) within 24 and 48 hours and (6) an access for all patients (whatever their cognitive status) to rehabilitation care, are all necessary conditions in a dedicated orthogeriatric unit for a reduction of mortality and the resumption of a rapid autonomy, especially for patients with dementia.

To prevent and manage the occurrence of possible delirium (avoidable with a $30 \%$ risk reduction when using a specialized geriatric intervention [32,37,38]), we used the recommendations proposed by Inouye et al $[31,32]$ every day of hospitalization. Delirium is common after hip fracture surgery (occurring in $35 \%$ to $65 \%$ of patients) [37], frequently associated with preexisting cognitive impairment and it is predictive of functional decline, institutionalization, and mortality $[33,37]$ : each day of delirium increased the risk of death within 6 months by $17 \%$ [34].

We show that dementia was not associated with the time-to-surgery (delay), suggesting that all actors of the perioperative period, particularly emergency physicians, orthopedic surgeons and anesthetists, managed these patients with the same accuracy.

Despite good results for mortality rate at 6 months and a lack of difference in 6-month walking ability (after taking into account their pre-existing conditions), DP and CSND patients were significantly more prone to new institutionalization compared to NDP patients. One of the main risk factors in our multivariate logistic regression was pre-fracture walking ability: patients who needed assistance to walk before surgery (more common in patients with dementia) had 2 times more likely to be newly institutionalized than the others. Despite an early geriatric intervention, $\mathrm{HF}$ remains a serious condition that precipitates time to institutionalization and this is probably ahead of the fracture time that we can act to prevent future loss of autonomy. 
Although this study cannot conclude to a causal link, our results suggests that an early implementation of a geriatric expertise in the management of hip fractured patients leads to dementia becoming comorbidity among others, and no longer a particularly serious comorbidity.

\subsection{Why we choose to create the group "CSND patients":}

We deliberately chose to create a group of CSND patients in order to be able to make effective comparisons because according to published literature, cognitive impairment remains under diagnosed [10], and because the situation of undetermined cognitive status of patients in perioperative care is frequent. CSND patients, with no diagnosis of dementia, would have been ranked among the patients without dementia and so, we would have been wrong to compare these two populations (potential differences would have been reduced). Indeed, despite missing data, this group was closer to DP patients (than NDP patients) since $17 \%$ of these patients had a diagnosis of dementia, and $20 \%$ of them were too severe to be explored according to MMSE score at 6 months. However, they were less often institutionalized before HF, probably due to a lack of medical care for a cognitive diagnosis that was not previously considered, or because they had less severe cognitive deterioration. Finally, CSND group was a heterogeneous group with patients with too severe cognitive disorder to be assessed, patients with early stage of cognitive disorder without assessment and patients without any conclusive cognitive information.

We obtained informations about cognitive disorder from patients, proxy, family and general practitioners because the use of scales is not always appropriate to the acute phase of hospitalization [2]. We do think that our groups were well defined, considering the time of management of these patients in the acute and preoperative period before HF surgery, and differences between the 3 groups (especially DP/CSND vs NDP) have strengthened our inclusion criteria and group constitution: 
- DP patients were less autonomous (ADL 3 [1-4]); they often lived in institutions (40\%) and suffered more often from postoperative delirium (56\%);

- NDP patients were more autonomous (ADL 6 [5-6]), they rarely lived in institutions (4\%), and they suffered less often from postoperative delirium (26\%).

\subsection{Limits}

This study had some limitations. It was an observational, single center study. Nonetheless, mono-centric studies ensure a high level of homogeneity in the way that data are collected and analyzed (we only had 11 patients lost to follow up). Although this study cannot conclude to a causal link, the impact of our orthogeriatric-dedicated unit on HF mortality in the population of patients with dementia should have been ideally studied by an interventional study (orthogeriatric-dedicated unit versus standard procedure). But, we previously published a study [26], showing that early admission to a dedicated geriatric unit improved 6-month mortality and morbidity in elderly patients with HF. After completion of this study [26], it could be considered not ethical to randomize patients between standard procedure and orthogeriatric-dedicated unit.

We did not have information about the degree of dementia and the date of diagnosis, known to be prognostic factors $[11,12,15,23,37]$. Because it was a retrospective study, we did not have systematic data on cognitive assessment at 6 months to better define CSND patients.

There is growing evidence from multiple studies that a similar benefit may be obtained elsewhere [2,39]. On these grounds, we anticipate that the deployment of new UPOG units in France as from 2014 will hopefully confirm these results, refine them and help find new ways to improve the outcome of patients facing HF surgery with or without cognitive disorders.

In conclusion, our study provides new information on the association between cognitive status before surgery and global outcomes. When cared for in a dedicated orthogeriatric care 
pathway, the global prognosis (mortality and functional outcome) of patients with dementia seems to be the same as patients without dementia.

Funding: This study was supported only by institutional sources.

Conflicts of interest: The authors declare that they have no conflict of interest.

Acknowledgments: We thank Mrs Diane Cohen for her valuable English proofreading. 


\section{REFERENCES:}

[1] Johnell O, Kanis JA (2006) An estimate of the worldwide prevalence and disability associated with osteoporotic fractures. Osteoporos Int 17, 1726-1733.

[2] Prestmo A, Hagen G, Sletvold O, Helbostad JL, Thingstad P, Taraldsen K, Lydersen S, Halsteinli V, Saltnes T, Lamb SE, Johnsen LG, Saltvedt I (2015) Comprehensive geriatric care for patients with hip fractures: a prospective, randomised, controlled trial. Lancet 385, 1623-1633.

[3] Gullberg B, Johnell O, Kanis JA (1997) World-wide projections for hip fracture. Osteoporos Int 7, 407-413.

[4] Stenvall M, Olofsson B, Lundström M, Englund U, Borssén B, Svensson O, Nyberg L, Gustafson Y (2007) A multidisciplinary, multifactorial intervention program reduces postoperative falls and injuries after femoral neck fracture. Osteoporos Int 18, 167-175.

[5] Johnell O (1997) The socioeconomic burden of fractures: today and in the 21st century. Am J Med 103, 20S-26S.

[6] Abrahamsen B, van Staa T, Ariely R, Olson M, Cooper C (2009) Excess mortality following hip fracture: a systematic epidemiological review. Osteoporos Int 20, $1633-1650$.

[7] Hannan EL, Magaziner J, Wang JJ, Eastwood EA, Silberzweig SB, Gilbert M, Morrison RS, McLaughlin MA, Orosz GM, Siu AL (2001) Mortality and Locomotion 6 Months After Hospitalization for Hip Fracture: Risk Factors and Risk-Adjusted Hospital Outcomes. JAMA 285, 2736-2742.

[8] Jackson TA, Naqvi SH, Sheehan B (2013) Screening for dementia in general hospital inpatients: a systematic review and meta-analysis of available instruments. Age Ageing 42, 689-695.

[9] Ferri CP, Prince M, Brayne C, Brodaty H, Fratiglioni L, Ganguli M, Hall K, Hasegawa K, Hendrie H, Huang Y, Jorm A, Mathers C, Menezes PR, Rimmer E, Scazufca M, Alzheimer's Disease International (2005) Global prevalence of dementia: a Delphi consensus study. Lancet 366, 2112-2117.

[10] Sampson EL, Blanchard MR, Jones L, Tookman A, King M (2009) Dementia in the acute hospital: prospective cohort study of prevalence and mortality. Br J Psychiatry 195, 61-66. 
[11] Weller I, Schatzher J (2004) Hip fractures and Alzheimer's disease in elderly institutionalized Canadians. Ann Epidemiol 14, 319-324.

[12] Baker NL, Cook MN, Arrighi HM, Bullock R (2011) Hip fracture risk and subsequent mortality among Alzheimer's disease patients in the United Kingdom, 1988-2007. Age Ageing 40, 49-54.

[13] Smith T, Pelpola K, Ball M, Ong A, Myint PK (2014) Pre-operative indicators for mortality following hip fracture surgery: a systematic review and meta-analysis. Age Ageing 43, 464-471.

[14] Diamantopoulos AP, Hoff M, Hochberg M, Haugeberg G (2013) Predictors of Short- and Long-Term Mortality in Males and Females with Hip Fracture - A Prospective Observational Cohort Study. PLoS ONE 8, e78169.

[15] Hershkovitz A, Polatov I, Beloosesky Y, Brill S (2010) Factors affecting mortality of frail hip-fractured elderly patients. Arch Gerontol Geriatr 51, 113-116.

[16] Clerencia-Sierra M, Calderón-Larrañaga A, Martínez-Velilla N, VergaraMitxeltorena I, Aldaz-Herce P, Poblador-Plou B, Machón-Sobrado M, EgüésOlazabal N, Abellán-van Kan G, Prados-Torres A (2015) Multimorbidity Patterns in Hospitalized Older Patients: Associations among Chronic Diseases and Geriatric Syndromes. PLoS ONE 10, e0132909.

[17] Fried LP, Tangen CM, Walston J, Newman AB, Hirsch C, Gottdiener J, Seeman T, Tracy R, Kop WJ, Burke G, McBurnie MA, Cardiovascular Health Study Collaborative Research Group (2001) Frailty in older adults: evidence for a phenotype. J Gerontol A Biol Sci Med Sci 56, M146-56.

[18] Huusko TM, Karppi P, Avikainen V, Kautiainen H, Sulkava R (2000) Randomised, clinically controlled trial of intensive geriatric rehabilitation in patients with hip fracture: subgroup analysis of patients with dementia. BMJ 321, 1107-1111.

[19] Adunsky A, Lusky A, Arad M, Heruti RJ (2003) A comparative study of rehabilitation outcomes of elderly hip fracture patients: the advantage of a comprehensive orthogeriatric approach. J Gerontol A Biol Sci Med Sci 58, 542547.

[20] Friedman SM, Mendelson DA, Bingham KW, Kates SL (2009) Impact of a Comanaged Geriatric Fracture Center on Short-term Hip Fracture Outcomes. Arch Intern Med 169, 1712-1717.

[21] Kammerlander C, Roth T, Friedman SM, Suhm N, Luger TJ, Kammerlander- 
Knauer U, Krappinger D, Blauth M (2010) Ortho-geriatric service--a literature review comparing different models. Osteoporos Int 21, 637-646.

[22] Deschodt M, Braes T, Broos P, Sermon A, Boonen S, Flamaing J, Milisen K (2011) Effect of an Inpatient Geriatric Consultation Team on Functional Outcome, Mortality, Institutionalization, and Readmission Rate in Older Adults with Hip Fracture: a Controlled Trial. J Am Geriatr Soc 59, 1299-1308.

[23] Stenvall M, Berggren M, Lundström M, Gustafson Y, Olofsson B (2012) A Multidisciplinary Intervention Program Improved the Outcome After Hip Fracture for People with Dementia-Subgroup Analyses of a Randomized Controlled Trial. Arch Gerontol Geriatr 54, e284-e289.

[24] Wagner P, Fuentes P, Diaz A, Martinez F, Amenabar P, Schweitzer D, Botello E, Gac H (2012) Comparison of complications and length of hospital stay between orthopedic and orthogeriatric treatment in elderly patients with a hip fracture. Geriatr Orthop Surg Rehabil 3, 55-58.

[25] Grigoryan KV, Javedan H, Rudolph JL (2014) Ortho-Geriatric Care Models and Outcomes in Hip Fracture Patients: A Systematic Review and Meta-Analysis. $J$ orthop Trauma 28, e49-e55.

[26] Boddaert J, Cohen-Bittan J, Khiami F, Le Manach Y, Raux M, Beinis J-Y, Verny M, Riou B (2014) Postoperative Admission to a Dedicated Geriatric Unit Decreases Mortality in Elderly Patients with Hip Fracture. PLoS ONE 9, e83795.

[27] Vallet H, Chenevier-Gobeaux C, Villain C, Cohen-Bittan J, Ray P, Epelboin L, Verny M, Riou B, Khiami F, Boddaert J (2016) Prognostic Value of Serum Procalcitonin After Orthopedic Surgery in the Elderly Population. J Gerontol A Biol Sci Med Sci 1-6.

[28] World Health Organization (2012) Dementia, a Public Health Priority.

[29] Linn BS, Linn MW, Gurel L (1968) Cumulative illness rating scale. J Am Geriatr Soc 16, 622-626.

[30] Katz S (1983) Assessing self-maintenance: activities of daily living, mobility, and instrumental activities of daily living. J Am Geriatr Soc 31, 721-727.

[31] Inouye SK, Westendorp RG, Saczynski JS (2014) Delirium in elderly people. Lancet 383, 911-922.

[32] Fong TG, Jones RN, Shi P, Marcantonio ER, Yap L, Rudolph JL, Yang FM, Kiely DK, Inouye SK (2009) Delirium accelerates cognitive decline in Alzheimer disease. Neurology 72, 1570-1575. 
[33] Liang C-K, Chu C-L, Chou M-Y, Lin Y-T, Lu T, Hsu C-J, Chen L-K (2014) Interrelationship of Postoperative Delirium and Cognitive Impairment and Their Impact on the Functional Status in Older Patients Undergoing Orthopaedic Surgery: A Prospective Cohort Study. PLoS ONE 9, e110339.

[34] Bellelli G, Mazzola P, Morandi A, Bruni A, Carnevali L, Corsi M, Zatti G, Zambon A, Corrao G, Olofsson B, Gustafson Y, Annoni G (2014) Duration of postoperative delirium is an independent predictor of 6-month mortality in older adults after hip fracture. J Am Geriatr Soc 62, 1335-1340.

[35] McGilton KS, Davis AM, Naglie G, Mahomed N, Flannery J, Jaglal S, Cott C, Stewart S (2013) Evaluation of patient-centered rehabilitation model targeting older persons with a hip fracture, including those with cognitive impairment. BMC Geriatr 13, 136.

[36] Al-Ani AN, Flodin L, Söderqvist A, Ackermann P, Samnegård E, Dalen N, Sääf M, Cederholm T, Hedström M (2010) Does rehabilitation matter in patients with femoral neck fracture and cognitive impairment? A prospective study of 246 patients. Arch Phy Med Rehabil 91, 51-57.

[37] Marcantonio ER, Flacker JM, Wright RJ, Resnick NM (2001) Reducing Delirium After Hip Fracture: A Randomized Trial. J Am Geriatr Soc 49, 516-522.

[38] Deschodt M, Braes T, Flamaing J, Detroyer E, Broos P, Haentjens P, Boonen S, Milisen K (2012) Preventing Delirium in Older Adults with Recent Hip Fracture Through Multidisciplinary Geriatric Consultation. J Am Geriatr Soc 60, 733-739.

[39] Sabharwal S, Wilson H (2015) Orthogeriatrics in the management of frail older patients with a fragility fracture. Osteoporos Int 26, 2387-99 
Figure 1: Flow Chart

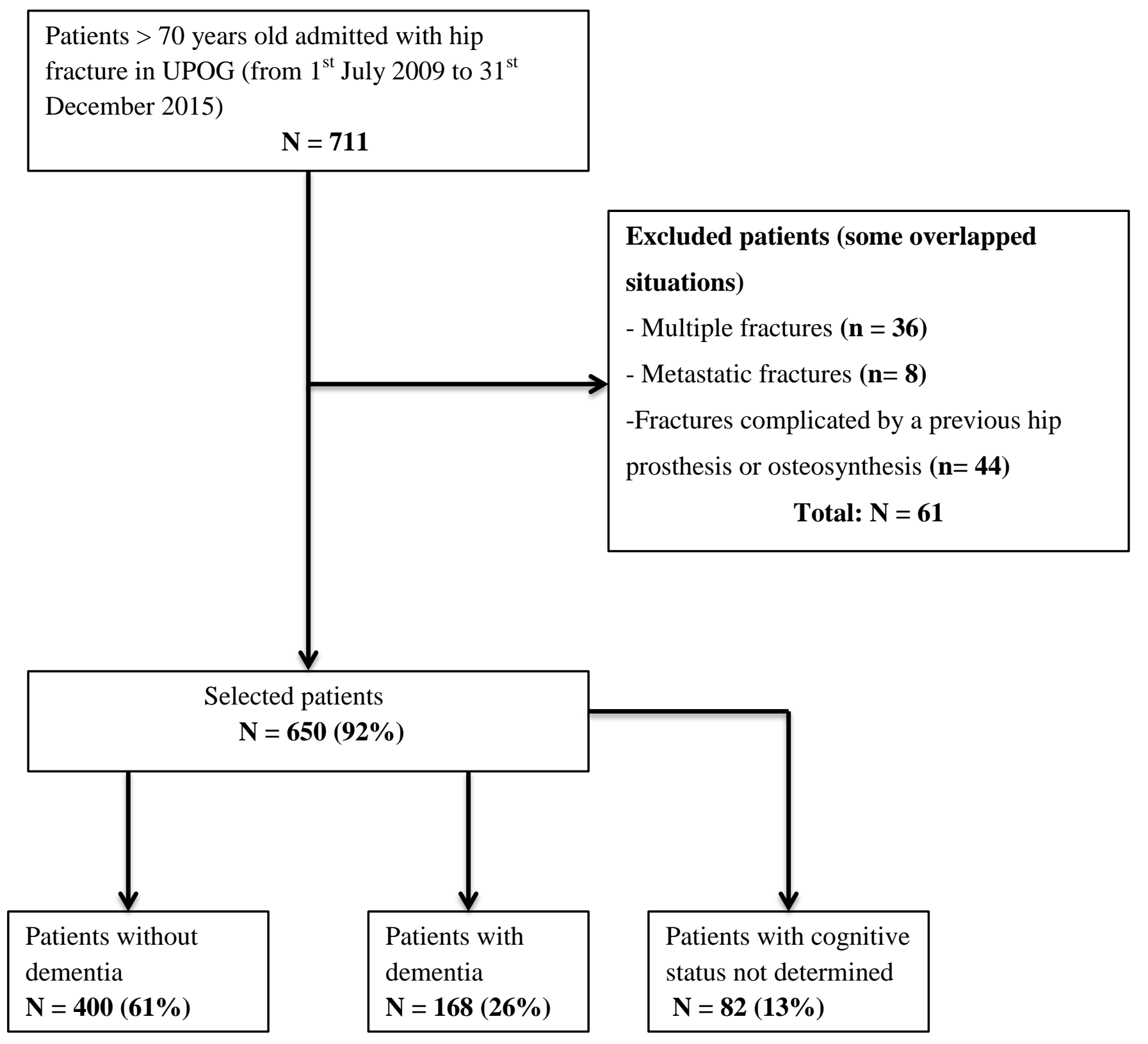


Table 1: Characteristics of the population and comparison of the main characteristics in the 3 groups of patients: without dementia (NDP), with cognitive status not determined (CSND) and with dementia (DP)

\begin{tabular}{|c|c|c|c|c|}
\hline & $\begin{array}{l}\text { All patients } \\
N=650\end{array}$ & $\begin{array}{l}\text { NDP } \\
N=400\end{array}$ & $\begin{array}{l}\text { DP } \\
N=168\end{array}$ & $\begin{array}{l}\text { CSND } \\
\mathbf{N}=\mathbf{8 2}\end{array}$ \\
\hline Age (years) & $86 \pm 6$ & $86 \pm 6$ & $87 \pm 6 * *$ & $89 \pm 6^{* * \$}$ \\
\hline Female & $495(76)$ & $298(74)$ & $135(80)$ & $62(76)$ \\
\hline \multicolumn{5}{|l|}{ Medical history } \\
\hline CIRS 52 & $9[6-12]$ & $8[6-11]$ & $10[8-12]^{* *}$ & $10[8-13]^{* *}$ \\
\hline Depression & $56(9)$ & $23(6)$ & $25(15)^{* *}$ & $8(10)$ \\
\hline Stroke & $112(17)$ & $66(16)$ & $34(20)$ & $12(15)$ \\
\hline Hypertension & $453(70)$ & $282(70)$ & $114(68)$ & $57(70)$ \\
\hline Diabetes & $78(12)$ & $54(14)$ & $12(7)^{* *}$ & $12(15)$ \\
\hline Obesity & $42(7)$ & $32(8)$ & $6(4)$ & $4(5)$ \\
\hline Atrial fibrillation & $177(27)$ & $101(25)$ & $47(28)$ & $29(35)$ \\
\hline Coronary artery disease & $119(18)$ & $73(18)$ & $17(29)$ & $17(21)$ \\
\hline Cardiac failure & $111(17)$ & $72(18)$ & $14(23)$ & $16(20)$ \\
\hline Thromboembolic disease & $54(8)$ & $30(10)$ & $11(7)$ & $5(6)$ \\
\hline COPD & $48(8)$ & $30(8)$ & $11(7)$ & $7(9)$ \\
\hline Chronic renal failure & $341(66)$ & $252(63)$ & $118(70)$ & $61(74)$ \\
\hline Cancer & $133(20)$ & $91(23)$ & $25(15)^{* *}$ & $17(21)$ \\
\hline Number of drugs per day & $5[3-8]$ & $5[3-8]$ & $6[4-8]^{* *}$ & $5[3-7]^{\$}$ \\
\hline \multicolumn{5}{|l|}{ Autonomy } \\
\hline ADL & $5[5-6]$ & $6[5-6]$ & $3[2-5]^{* *}$ & $5[3-6]^{* * \$}$ \\
\hline $\mathrm{ADL}=6$ & $340(53 \%)$ & $283(71 \%)$ & $33(21 \%)$ & $24(30 \%)$ \\
\hline Living in institution & $102(16)$ & $16(4)$ & $73(43) * *$ & $13(16)^{* * \$}$ \\
\hline Living at home with assistance & $517(80)$ & $292(73)$ & $157(93)^{* *}$ & $67(82)^{\$}$ \\
\hline \multicolumn{5}{|l|}{ Walking ability } \\
\hline Walking & $632(97)$ & $393(98)$ & $160(95)^{* *}$ & $79(96)$ \\
\hline Walking with assistance & $332(51)$ & $184(46)$ & $101(60)^{* *}$ & $47(57)$ \\
\hline Repeated falls & $316(49)$ & $151(38)$ & $119(71)^{* *}$ & $46(56) * * \$$ \\
\hline \multicolumn{5}{|l|}{ Fracture } \\
\hline Intertrochanteric fracture & $337(52)$ & $214(56)$ & $87(52)$ & $42(51)$ \\
\hline Femoral neck fracture & $313(48)$ & $171(44)$ & $81(48)$ & $40(49)$ \\
\hline \multicolumn{5}{|l|}{ Surgery } \\
\hline Time to surgery (h) & $23[14-36]$ & $23[14-33]$ & $24[14-37]$ & $25[13-42]$ \\
\hline Time to surgery $>48$ hours & $89(14)$ & $40(12)$ & $24(15)$ & $16(20)$ \\
\hline Duration of surgery (min) & $130[110-160]$ & $130[110-160]$ & $120[110-150]$ & $120[100-147]^{* *}$ \\
\hline Time to UPOG (h) & $38[25-63]$ & $38[26-66]$ & $36[25-64]$ & $34[24-57]$ \\
\hline Gamma nail & $339(52)$ & $207(53)$ & $84(52)$ & $38(47)$ \\
\hline Dynamic hip screw & $54(8)$ & $31(8)$ & $8(5)$ & $10(12)$ \\
\hline Unipolar prosthesis & $242(38)$ & $141(36)$ & $67(41)$ & $34(42)$ \\
\hline Bipolar prosthesis & $15(2)$ & $12(3)$ & $3(2)$ & $0(0)$ \\
\hline \multicolumn{5}{|l|}{ Hemoglobin } \\
\hline Preoperative hemoglobin $\left(\mathrm{g} \cdot \mathrm{dL}^{-1}\right)$ & $12.2 \pm 1.6$ & $12.3 \pm 1.7$ & $12.0 \pm 1.7$ & $12.1 \pm 1.5$ \\
\hline Preoperative anemia & $294(45)$ & $171(43)$ & $83(49)$ & $40(49)$ \\
\hline
\end{tabular}

- $\quad$ Data are mean \pm SD, median [25-75 interquartile], or number (percentage).

- $\quad * *$ : Comparison with NDP; $\$$ Comparison with DP $=\mathrm{p}<0.05$ : Comparison between 3 groups was performed using the Kruskal Wallis test followed by the Dunn test for quantitative variables, and Fisher's exact method for qualitative variables

- CIRS: cumulative illness rating scale; COPD: chronic obstructive pulmonary disease; ADL: activity daily living; UPOG: post-operative geriatric unit. Obesity defined as body mass index $>30 \mathrm{~kg} . \mathrm{m} 2$. Anemia was defined by $\mathrm{Hb}$ level $<12 \mathrm{~g}^{\mathrm{dL}} \mathrm{dL}^{-1}$ in women and $13 \mathrm{~g}$. $\mathrm{dL} \mathrm{w}^{-1}$ in men $\mathrm{h}=$ hours; $\mathrm{m}=$ minutes 
Table 2. Post-operative complications and 6-month outcomes in the 3 groups of patients: without dementia (NDP), with cognitive status not determined (CSND) and with dementia (DP)

\begin{tabular}{|c|c|c|c|c|}
\hline & $\begin{array}{l}\text { All patients } \\
N=650\end{array}$ & $\begin{array}{l}\text { NDP } \\
N=400\end{array}$ & $\begin{array}{l}D P \\
N=168\end{array}$ & $\begin{array}{l}\text { CSND } \\
\mathrm{N}=82\end{array}$ \\
\hline Time to first sitting (days) & $1[1-2]$ & $1[1-2]$ & $1[1-2]$ & $1[1-3]^{\$}$ \\
\hline Time to first walking (days) & $2[1-4]$ & $2[1-4]$ & $2[1-3]$ & $3[2-4]^{* * \$}$ \\
\hline \multicolumn{5}{|l|}{ Post-operative complications } \\
\hline Delirium & $254(39)$ & $105(26)$ & $99(59)^{* *}$ & $50(61)^{* *}$ \\
\hline Pain & $621(96)$ & $384(96)$ & $156(93)$ & $81(99)^{\$}$ \\
\hline Morphine administration & $586(90)$ & $359(90)$ & $153(91)$ & $74(90)$ \\
\hline Min. in-hosp hemoglobin $\left(\mathrm{g} / \mathrm{dL}^{-1}\right)$ & $9.2 \pm 1.4$ & $9.2 \pm 1.4$ & $9.3 \pm 1.4$ & $9.1 \pm 1.6$ \\
\hline In-hospital transfusion & $357(53)$ & $223(56)$ & $87(52)$ & $47(57)$ \\
\hline Total packed RBC per patient & $1[0-2]$ & $1[0-2]$ & $1[0-2]$ & $1[0-2]$ \\
\hline Stool impaction & $277(43)$ & $164(41)$ & $78(46)$ & $35(43)$ \\
\hline Urinary retention & $168(26)$ & $108(27)$ & $39(23)$ & $21(26)$ \\
\hline Pressure ulcer & $79(12)$ & $47(12)$ & $20(12)$ & $12(15)$ \\
\hline Acute heart failure & $83(13)$ & $54(14)$ & $13(8)$ & $16(20)^{\$}$ \\
\hline Acute coronary syndrome & $68(10)$ & $40(10)$ & $17(10)$ & $11(13)$ \\
\hline Acute atrial fibrillation & $57(9)$ & $34(8)$ & $16(10)$ & $7(9)$ \\
\hline Infection & $121(19)$ & $68(17)$ & $37(22)$ & $16(20)$ \\
\hline Acute thromboembolism disease & $29(5)$ & $16(4)$ & $7(4)$ & $6(7)$ \\
\hline Admission into ICU & $31(5)$ & $23(6)$ & $3(2)^{* *}$ & $5(6)$ \\
\hline LOS (days) & $11[9-15]$ & $11[9-15]$ & $11[8-14]$ & $13[10-17]^{* * \$}$ \\
\hline Death during hospitalization & $23(4)$ & $16(4)$ & $2(1)$ & $5(6)^{\$}$ \\
\hline Walking at discharge & $568(88)$ & $351(89)$ & $149(89)$ & $68(84)$ \\
\hline $\begin{array}{l}\text { Walking with assistance at } \\
\text { discharge }\end{array}$ & $546(86)$ & $344(88)$ & $138(83)$ & $64(84)^{* *}$ \\
\hline Admission to rehabilitation care & $514(79)$ & $335(84)$ & $113(67)^{* *}$ & $66(80)^{\$}$ \\
\hline Home return $^{\mathrm{a}}$ & $102(16)$ & $41(10)$ & $51(30)^{* *}$ & $10(12)^{\$}$ \\
\hline \multicolumn{5}{|l|}{ After 6 months } \\
\hline Walk with assistance $(\mathrm{MD}=26)$ & $331(63)$ & $209(64)$ & $85(61)$ & $37(62)$ \\
\hline ADL score $(\mathrm{MD}=323)$ & $4[2-5]$ & $5[3-6]$ & $2[1-4]^{* *}$ & $3[2-5]^{* * \$}$ \\
\hline $\begin{array}{l}\text { Newly institutionalized patients } \\
(\mathrm{MD}=11)\end{array}$ & $81(12)$ & $30(8)$ & $32(19)^{* *}$ & $10(23)^{* *}$ \\
\hline Death $(\mathrm{MD}=11)$ & $97(15)$ & $53(14)$ & $26(16)$ & $18(22)^{* *}$ \\
\hline Home return $^{\mathrm{a}}(\mathrm{MD}=33)$ & $464(89)$ & $296(92)$ & $118(84)^{* *}$ & $50(85)$ \\
\hline
\end{tabular}

- Data are mean $\pm \mathrm{SD}$, median [25-75 interquartile], or number (percentage).

- $\quad * *$ : Comparison with NDP; \$ Comparison with DP = p <0.05: Comparison between 3 groups was performed using the Kruskal Wallis test followed by the Dunn test for quantitative variables, and Fisher's exact method for qualitative variables

- ADL: activity daily living; UPOG: post-operative geriatric unit. LOS: length of stay. ICU: Intensive care unit. RBC: red blood cell

- $\quad$ MD: Missing data 
Table 3. Multivariate logistic regression analysis predicting the risk of delirium, the opportunity to go to rehabilitation care at discharge, death and new institutionalization at 6 month

\begin{tabular}{|c|c|c|}
\hline Variables & OR $[95 \% \mathrm{CI}]$ & P value \\
\hline \multicolumn{3}{|l|}{ Prediction of delirium after surgery $(\mathrm{AIC}=\mathbf{7 0 4})$} \\
\hline \multicolumn{3}{|l|}{ Age, reference value $\leq 80$ years } \\
\hline - $\quad$ Age 81-85 & $1.57[0.85-2.96]$ & 0.15 \\
\hline - $\quad$ Age 86-90 & $2.13[1.21-3.83]$ & $0.009 *$ \\
\hline - $\quad$ Age $>90$ & $2.06[1.12-3.85]$ & $0.002 *$ \\
\hline \multicolumn{3}{|l|}{ Sex, reference value $=$ female } \\
\hline - $\quad$ Male $=$ yes & $1.52[0.98-2.36]$ & 0.06 \\
\hline \multicolumn{3}{|l|}{ CIRS 52, reference value $\leq 9$} \\
\hline$-\quad$ CIRS $>9$ & $1.17[0.78-1.76]$ & 0.43 \\
\hline \multicolumn{3}{|l|}{ Number of drugs per day, reference value $<5$} \\
\hline - $\quad$ Number of drugs per day $\geq 5$ & $0.99[0.66-1.50]$ & 0.99 \\
\hline \multicolumn{3}{|l|}{ Pre-fracture ADL6, reference value $=6$} \\
\hline - $\quad$ Pre-fracture ADL $\leq 5$ & $1.67[1.08-2.58]$ & $0.02 *$ \\
\hline \multicolumn{3}{|c|}{ Walking before fracture without assistance, reference value $=$ yes } \\
\hline Walking before fracture with assistance & $0.81[0.54-1.22]$ & 0.32 \\
\hline \multicolumn{3}{|l|}{ Transfusion during hospitalization, reference value $=$ No } \\
\hline - Transfusion during hospitalization: Yes & $1.74[1.19-2.55]$ & $0.005^{*}$ \\
\hline \multicolumn{3}{|l|}{ Time to first sitting, reference value $\leq 1$} \\
\hline - $\quad$ Time to first sitting $>1$ & $1.09[0.75-1.59]$ & 0.65 \\
\hline \multicolumn{3}{|l|}{ Time to surgery, reference value $\leq 48$ hours } \\
\hline - $\quad$ Delay $>48$ hours & $0.95[0.56-1.61]$ & 0.85 \\
\hline \multicolumn{3}{|l|}{ Cognitive status, reference value $=$ Without dementia } \\
\hline - $\quad$ Patients with dementia & $3.12[1.97-4.96]$ & $<0.001 *$ \\
\hline - Patients with cognitive status not determined & $3.30[1.87-5.80]$ & $<0.001 *$ \\
\hline
\end{tabular}

Prediction of admission to rehabilitation care at discharge $(\mathrm{AIC}=596)$

Age, reference value $\leq \mathbf{8 0}$ years

- $\quad$ Age 81-85

$\begin{array}{ll}1.44[0.72-2.95] & 0.30 \\ 1.40[0.74-2.76] & 0.32 \\ 1.45[0.73-2.99] & 0.29\end{array}$

- $\quad$ Age $>90$

$1.45[0.73-2.99] \quad 0.29$

Sex, reference value $\boldsymbol{=}$ female

- $\quad$ Male $=$ yes

$0.99[0.60-1.64] \quad 0.98$

CIRS 52, reference value $\leq 9$

- $\quad$ CIRS $>9$

Number of drugs per day, reference value $<5$

- $\quad$ Number of drugs per day $\geq 5$

Pre-fracture ADL6, reference value = 6

- Pre-fracture ADL $\leq 5$

Walking before fracture without assistance, reference value $=$ yes

- Walking before fracture with assistance

$0.95[0.60-1.51] \quad 0.83$

Time to surgery, reference value $\leq \mathbf{4 8}$ hours

- $\quad$ Delay $>48$ hours

$1.05[0.66-1.67] \quad 0.82$

$2.36[1.41-3.97] \quad 0.001^{*}$

$0.60[0.37-0.93] \quad 0.02 *$

$0.81[0.43-1.45] \quad 0.49$

Delirium, reference value $=$ no

- $\quad$ Delirium $=$ Yes

Cognitive status, reference value $=$ Without dementia

- Patients with dementia

- Patients with cognitive status not determined

$1.21[0.77-1.88] \quad 0.41$

$1.53[0.91-2.55] \quad 0.10$

$0.90[0.44-1.76] \quad 0.77$ 
Prediction of death at 6 month $(\mathrm{AIC}=483)$

Age, reference value $\leq \mathbf{8 0}$ years

- $\quad$ Age 81-85

$0.95[0.41-2.19] \quad 0.90$

- $\quad$ Age 86-90

$1.22[0.58-2.66] \quad 0.61$

- $\quad$ Age $>90$

$1.38[0.63-3.13]$

0.43

Sex, reference value $=$ female

- $\quad$ Male $=$ yes

$1.55[0.88-2.68] \quad 0.12$

CIRS 52, reference value $\leq 9$

- $\quad$ CIRS > 9

$1.75[1.04-2.98] \quad 0.04 *$

Number of drugs per day, reference value $<5$

- Number of drugs per day $\geq 5$

$1.24[0.72-2.18] \quad 0.44$

Pre-fracture ADL6, reference value = 6

- Pre-fracture ADL $\leq 5$

Walking before fracture without assistance, reference value $=$ yes

- Walking before fracture with assistance

$2.45[1.40-4.38] \quad 0.002 *$

$1.93[1.13-3.39] \quad 0.02 *$

Time to surgery, reference value $\leq \mathbf{4 8}$ hours

- $\quad$ Delay $>48$ hours

$1.21[0.63-2.21] \quad 0.55$

Delirium, reference value $=$ no

- $\quad$ Delirium $=$ Yes

Cognitive status, reference value $=$ Without dementia

- Patients with dementia

- Patients with cognitive status not determined

$1.01[0.66-1.81] \quad 0.70$

$0.65[0.35-1.17] \quad 0.16$

$0.90[0.44-1.80] \quad 0.79$

Prediction of new institutionalization at 6 month $(\mathrm{AIC}=443)$

Age, reference value $\leq \mathbf{8 0}$ years

- $\quad$ Age 81-85 $\quad 1.03[0.41-2.65] \quad 0.95$

- $\quad$ Age 86-90 $1.27[0.57-3.07] \quad 0.57$

- $\quad$ Age $>90 \quad 1.42[0.61-3.54] \quad 0.42$

Sex, reference value $=$ female

- $\quad$ Male $=$ yes

$0.80[0.40-1.51] \quad 0.51$

CIRS 52, reference value $\leq 9$

- $\quad$ CIRS $>9$

Number of drugs per day, reference value $<5$

- Number of drugs per day $\geq 5$

Pre-fracture ADL6, reference value $=6$

- Pre-fracture ADL $\leq 5$

Walking before fracture without assistance, reference value $=$ yes

- Walking before fracture with assistance

Time to surgery, reference value $\leq \mathbf{4 8}$ hours

- $\quad$ Delay $>48$ hours

Delirium, reference value $=$ no

- $\quad$ Delirium $=$ Yes

Cognitive status, reference value $=$ Without dementia

- Patients with demi

- Patients with cognitive status not determined

$1.08[0.62-1.87] \quad 0.78$

$0.98[0.56-1.75] \quad 0.96$

$0.89[0.49-1.65] \quad 0.72$

$2.00[1.14-3.60] \quad 0.02 *$

$0.55[0.22-1.20] \quad 0.16$

$1.15[0.67-1.97] \quad 0.60$

CI: confidence interval; CIRS: cumulative illness rating scale; ADL: activity daily living; OR: Odds Ratio

AIC : Akaike Information Criterion

There was 11 missing data for death at 6 months and new institutionalization at 6 months; we excluded these patients from the analysis $(1,7 \%)$. 
Figure 2: Survival curves for mortality adjusted for age, sex, Cumulative Illness Rating Scale, number of drugs per day, pre-fracture ADL6, walking before fracture with assistance, time to surgery, delirium and cognitive status (calculated with a Cox regression analysis).

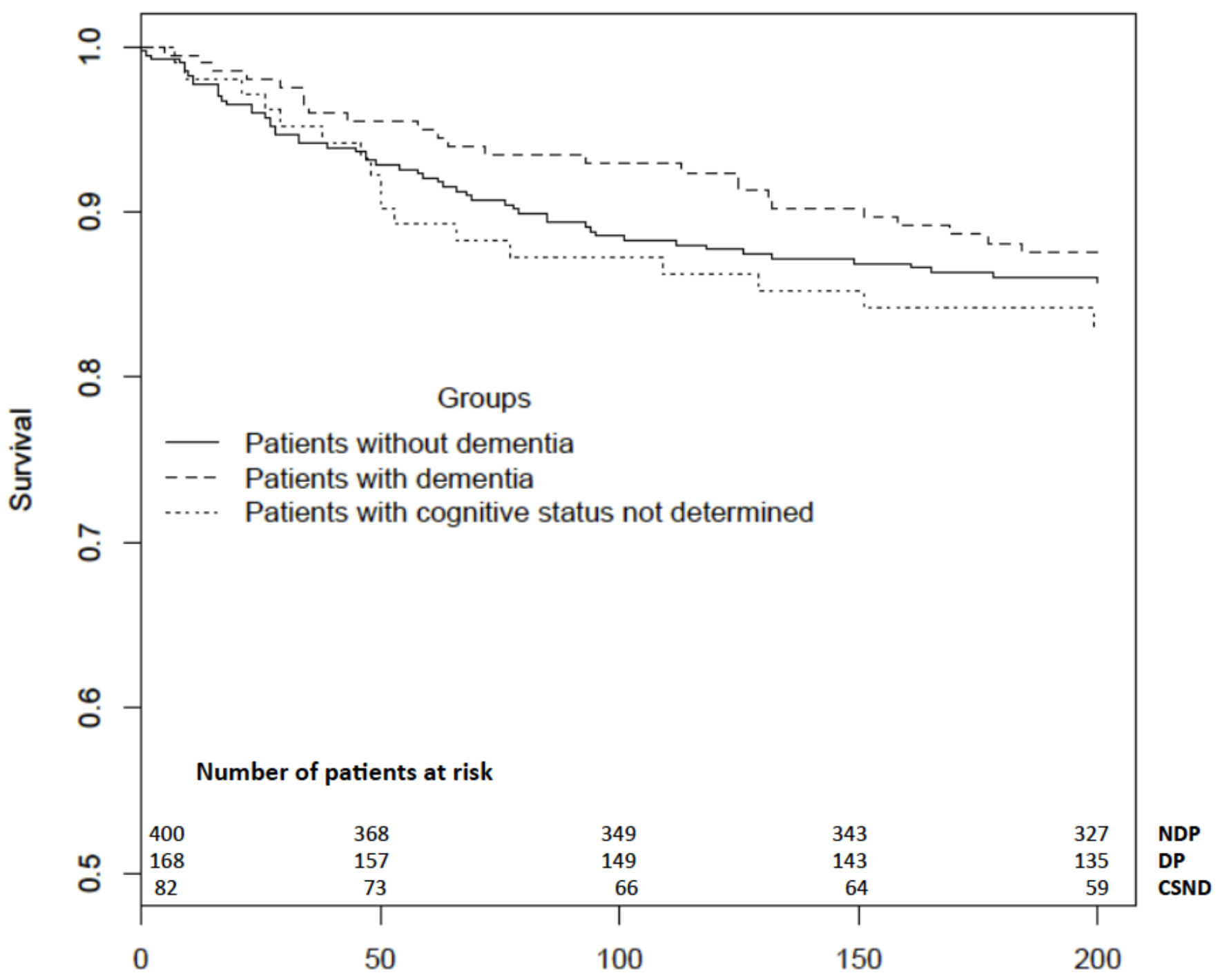

Days after admission

- P logrank: patients with dementia vs patient without dementia: $0.18 ; \mathrm{C}$ Index $=0.60$

- P logrank: patients with dementia vs cognitive status not determined: $0.29 ; \mathrm{C}$ index $=0.70$

- P logrank: cognitive status not determined vs patient without dementia: $0.62 ; \mathrm{C}$ Index $=0.58$ 
APPENDIX 1: Patients without dementia vs Patients with dementia: Multivariate cox proportionalhazards analysis predicting death and new-institutionalization in the first 6 months

\begin{tabular}{|c|c|c|}
\hline Variables & Hazard Ratio [95\% CI] & $P$ value \\
\hline \multicolumn{3}{|l|}{ Prediction of death } \\
\hline \multicolumn{3}{|l|}{ Age, reference value $\leq 80$ years } \\
\hline - $\quad$ Age 81-85 & $0.91[0.36-2.31]$ & 0.85 \\
\hline - $\quad$ Age $86-90$ & $0.63[0.28-1.40]$ & 0.25 \\
\hline$-\quad$ Age $>90$ & $0.84[0.36-1.98]$ & 0.70 \\
\hline \multicolumn{3}{|l|}{ Sex , reference value $=$ female } \\
\hline - $\quad$ Male $=$ yes & $0.92[0.50-1.70]$ & 0.80 \\
\hline \multicolumn{3}{|l|}{ CIRS 52, reference value $\leq 9$} \\
\hline$-\quad$ CIRS $>9$ & $1.24[0.64-2.40]$ & 0.52 \\
\hline \multicolumn{3}{|l|}{ Number of drugs per day, reference value $<5$} \\
\hline - Number of drugs per day $\geq 5$ & $0.92[0.50-1.72]$ & 0.81 \\
\hline \multicolumn{3}{|l|}{ Pre-fracture ADL6, reference value $=6$} \\
\hline - $\quad$ Pre-fracture ADL $\leq 5$ & $1.04[0.53-2.02]$ & 0.90 \\
\hline \multicolumn{3}{|c|}{ Walking before fracture without assistance, reference value = yes } \\
\hline - Walking before fracture with assistance & $1.67[0.80-3.45]$ & 0.17 \\
\hline \multicolumn{3}{|l|}{ Time to surgery, reference value $\leq 48$ hours } \\
\hline - $\quad$ Delay $>48$ hours & $1.54[0.73-3.24]$ & 0.26 \\
\hline \multicolumn{3}{|l|}{ Delirium, reference value $=$ no } \\
\hline - $\quad$ Delirium $=$ Yes & $1.21[0.70-2.14]$ & 0.48 \\
\hline \multicolumn{3}{|c|}{ Cognitive status, reference value $=$ Without dementia } \\
\hline - Patients with dementia & $0.67[0.38-1.20]$ & 0.18 \\
\hline
\end{tabular}

CI: confidence interval; CIRS: cumulative illness rating scale. *: P $<0.05$

a: Only patients who were not previously living in an institution were considered and death was considered as a censored observation.

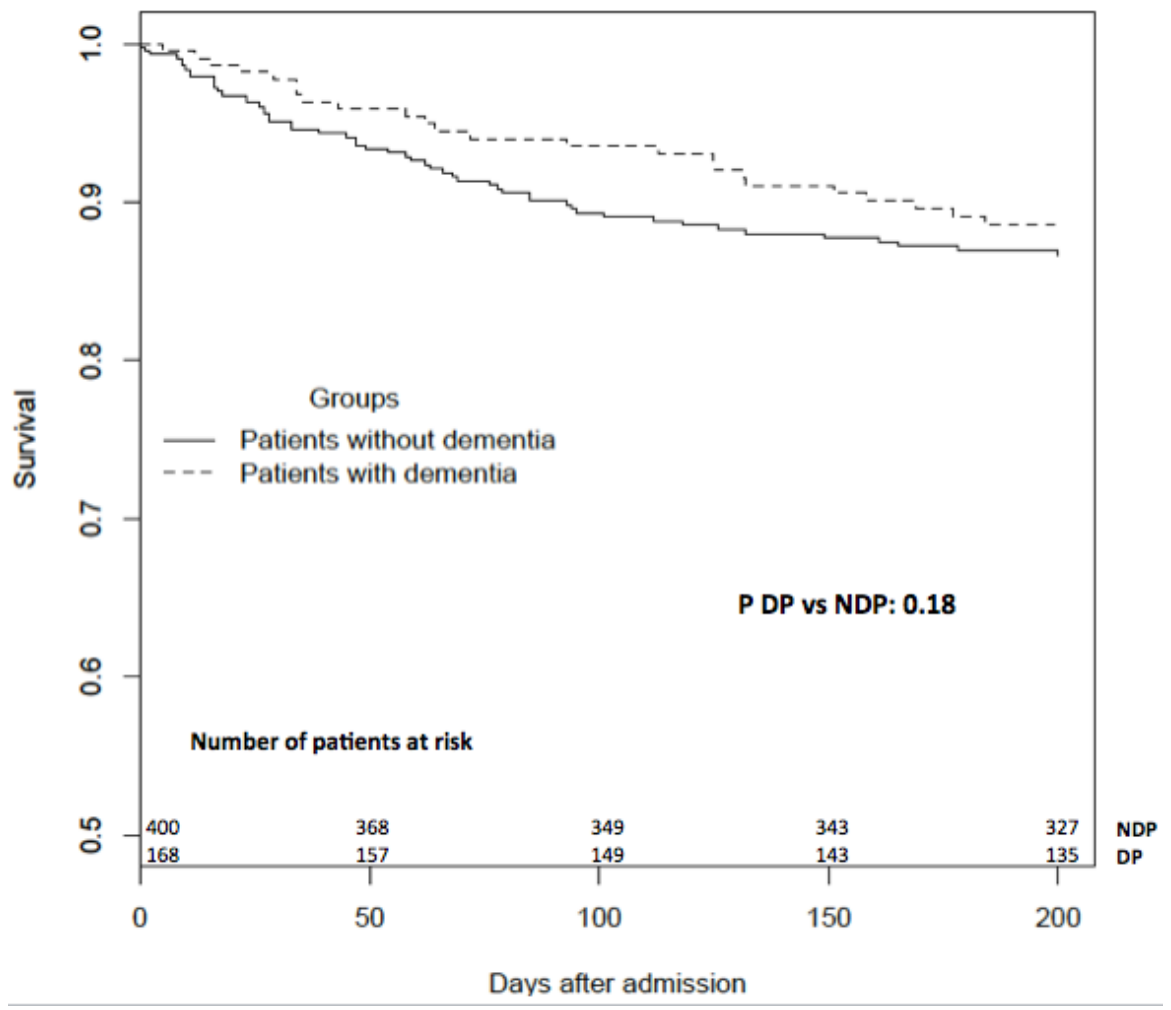


APPENDIX 2: Patients with dementia vs Patients with cognitive status non determined: Multivariate cox proportional-hazards analysis predicting death and new-institutionalization in the first 6 months

\begin{tabular}{|c|c|c|}
\hline Variables & Hazard Ratio [95\% CI] & P value \\
\hline \multicolumn{3}{|l|}{ Prediction of death } \\
\hline \multicolumn{3}{|l|}{ Age, reference value $\leq 80$ years } \\
\hline - $\quad$ Age 81-85 & $0.64[0.14-2.97]$ & 0.57 \\
\hline - $\quad$ Age 86-90 & $1.35[0.35-5.21]$ & 0.66 \\
\hline - $\quad$ Age $>90$ & $0.64[0.16-2.60]$ & 0.53 \\
\hline \multicolumn{3}{|l|}{ Sex, reference value $=$ female } \\
\hline - $\quad$ Male $=$ yes & $0.65[0.22-1.96]$ & 0.44 \\
\hline \multicolumn{3}{|l|}{ CIRS 52, reference value $\leq 9$} \\
\hline$-\quad$ CIRS $>9$ & $0.71[0.30-1.70]$ & 0.45 \\
\hline \multicolumn{3}{|l|}{ Number of drugs per day, reference value $<5$} \\
\hline - Number of drugs per day $\geq 5$ & $0.80[0.29-2.26]$ & 0.68 \\
\hline \multicolumn{3}{|l|}{ Pre-fracture ADL6, reference value $=6$} \\
\hline - $\quad$ Pre-fracture ADL $\leq 5$ & $0.16[0.04-0.65]$ & $0.009 *$ \\
\hline \multicolumn{3}{|c|}{ Walking before fracture without assistance, reference value = yes } \\
\hline - Walking before fracture with assistance & $0.62[0.24-1.61]$ & 0.32 \\
\hline \multicolumn{3}{|l|}{ Time to surgery, reference value $\leq 48$ hours } \\
\hline - $\quad$ Delay $>48$ hours & $1.40[0.52-3.77]$ & 0.51 \\
\hline \multicolumn{3}{|l|}{ Delirium, reference value $=$ no } \\
\hline - $\quad$ Delirium $=$ Yes & $1.90[0.72-5.03]$ & 0.19 \\
\hline \multicolumn{3}{|c|}{ Cognitive status, reference value $=$ cognitive status not determined } \\
\hline - Patients with dementia & $0.65[0.28-1.45]$ & 0.29 \\
\hline
\end{tabular}

CI: confidence interval; CIRS: cumulative illness rating scale. *: $\mathrm{P}<0.05$

a: Only patients who were not previously living in an institution were considered and death was considered as a censored observation.

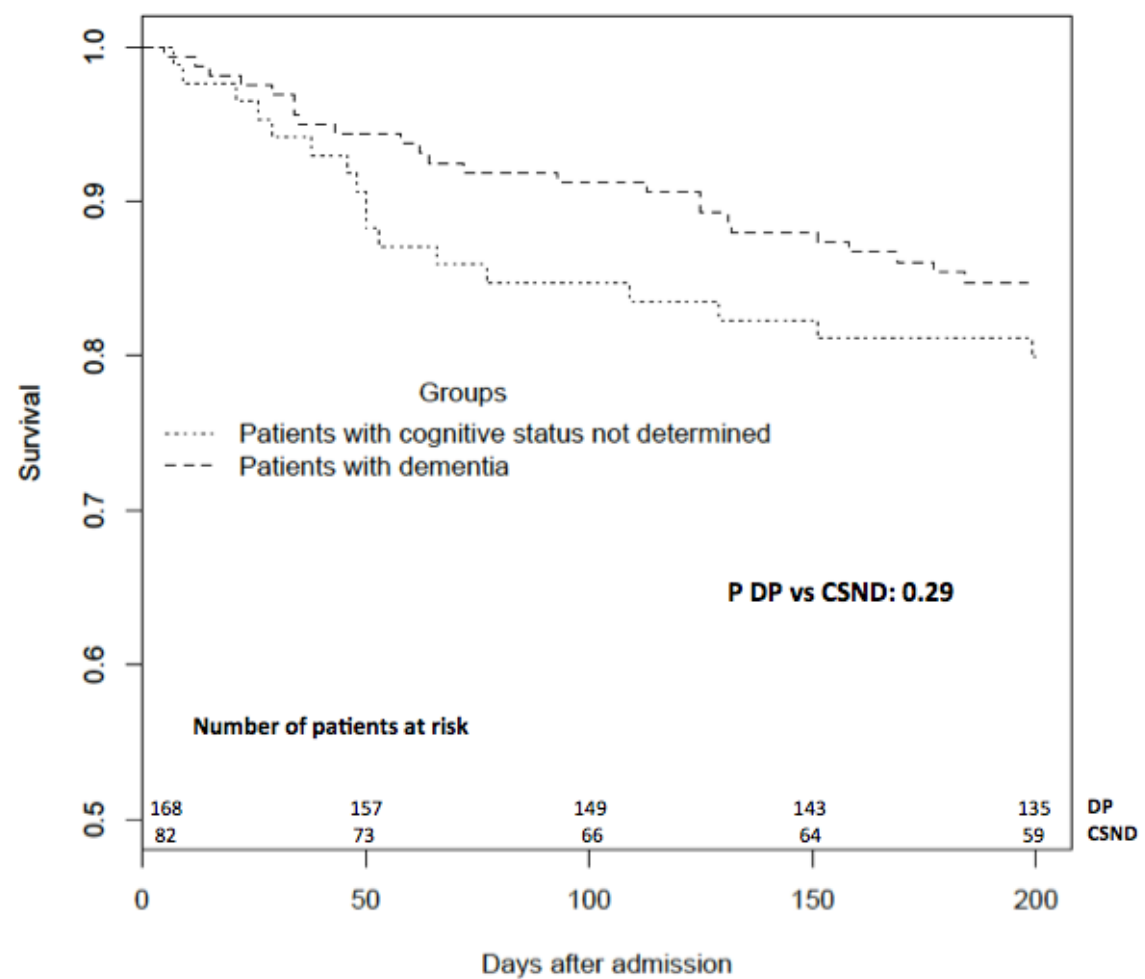


APPENDIX 3: Patients without dementia vs patients with cognitive status non determined: Multivariate cox proportional-hazards analysis predicting death and new-institutionalization in the first 6 months

\begin{tabular}{|c|c|c|}
\hline Variables & Hazard Ratio $[95 \% \mathrm{CI}]$ & P value \\
\hline \multicolumn{3}{|l|}{ Prediction of death } \\
\hline \multicolumn{3}{|l|}{ Age, reference value $\leq \mathbf{8 0}$ years } \\
\hline - $\quad$ Age $81-85$ & $0.95[0.38-2.34]$ & 0.91 \\
\hline - $\quad$ Age $86-90$ & $0.60[0.25-1.45]$ & 0.26 \\
\hline$-\quad$ Age $>90$ & $0.64[0.27-1.51]$ & 0.31 \\
\hline \multicolumn{3}{|l|}{ Sex, reference value $=$ female } \\
\hline - $\quad$ Male $=$ yes & $0.78[0.43-1.44]$ & 0.43 \\
\hline \multicolumn{3}{|l|}{ CIRS 52, reference value $\leq 9$} \\
\hline$-\quad$ CIRS $>9$ & $0.99[0.53-1.86]$ & 0.99 \\
\hline \multicolumn{3}{|l|}{ Number of drugs per day, reference value $<5$} \\
\hline - $\quad$ Number of drugs per day $\geq 5$ & $1.02[0.55-1.91]$ & 0.94 \\
\hline \multicolumn{3}{|l|}{ Pre-fracture ADL6, reference value $=6$} \\
\hline - $\quad$ Pre-fracture ADL $\leq 5$ & $1.11[0.58-2.15]$ & 0.74 \\
\hline \multicolumn{3}{|c|}{ Walking before fracture without assistance, reference value $=$ yes } \\
\hline - Walking before fracture with assistance & $1.70[0.86-3.38]$ & 0.13 \\
\hline \multicolumn{3}{|l|}{ Time to surgery, reference value $\leq 48$ hours } \\
\hline - $\quad$ Delay $>48$ hours & $1.32[0.67-2.61]$ & 0.42 \\
\hline \multicolumn{3}{|l|}{ Delirium, reference value $=$ no } \\
\hline - $\quad$ Delirium $=$ Yes & $1.25[0.71-2.21]$ & 0.43 \\
\hline \multicolumn{3}{|l|}{ Cognitive status, reference value $=$ Without dementia } \\
\hline - $\quad$ Patients with cognitive status not determined & $0.84[0.41-1.68]$ & 0.62 \\
\hline
\end{tabular}

CI: confidence interval; CIRS: cumulative illness rating scale. *: $\mathrm{P}<0.05$

a: Only patients who were not previously living in an institution were considered and death was considered as a censored observation.

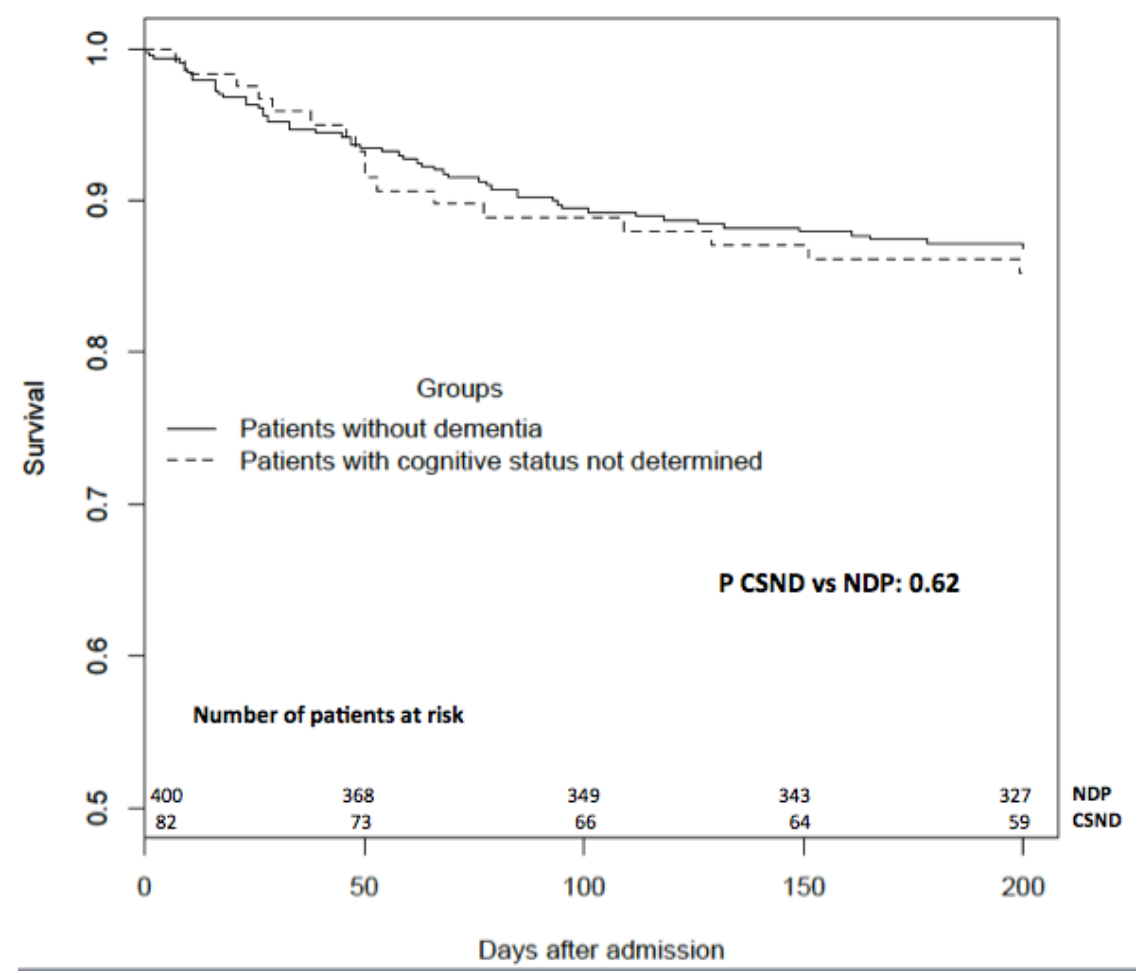

